\title{
Project method of training the student designers on the example of regional identification logos and signs' creation
}

\author{
Natalia Kozhina ${ }^{1, *}$, Elena Kostyrina ${ }^{1}$ \\ ${ }^{1}$ Don State Technical University, 1, Gagarin sq., 344010, Rostov-on-Don, Russia
}

\begin{abstract}
The article explores the design method of creating a logo as a graphic basis for visual branding. The identification importance for the promotion of goods and services, as well as in the field of regional branding, is substantiated. The task of creating an identity is considered in the context of the formal characteristics and the substantive aspect unity. A detailed description of the author's methodology for the development of the regional identification logos and signs in the process of training the design students is given. The focus is on the need for a thorough analysis of the design task and the systematization of analog material for the conceptual solutions' selection. An algorithm for step-by-step actions in the designed sign expressiveness compositional means' selection using such resources as typography and illustration, is proposed. The criteria for assessing the design result quality - a composite and imaginative solution in creating the signs of regional identification are given. The multidisciplinary nature of this design task is emphasized.
\end{abstract}

\section{Introduction}

At the present stage, the market of goods and services is in a fierce competition state. In these conditions, the importance of brand awareness of a company participating in market relations is being updated. The unique design of the organization's logo is able to attract and retain the consumer's attention, significantly distinguish the brand among the competitors, because in the corporate identity system, the logo is a distinctive part of the visual brand, identifier and determining factor when being chosen [1].

Design, first of all, defines the identity elements' formal properties. However, without conceptual content, the logo becomes a lifeless graphic image and, as a result, loses its attractiveness. The viewer may not be a professional, but at the mental level he necessarily feels the primitive decisions, devoid of deep meaning and figurative expressiveness.

At the initial stage of creating a logo, to achieve the maximum result, it is important to separate the concepts of the concept and the graphic language's expression form [2]. Inarticulate ideas can negatively transform the attitude to the brand, create unnecessary associations, images and create a situation of the reputation risk.

\footnotetext{
*Corresponding author: prirona@mail.ru
} 
The aim of the study is a systematic analysis of logo design approaches in the context of the unity of form and content. The presented methodology is based on experience in the design practice and has been successfully used in teaching. It involves the consistent execution of tasks that organize and develop a design student's thinking. This technique is considered in the article on the example of developing a logo sign in the context of a regional aspect.

\section{Understanding the topic of design and problem statement}

An urgent task for the Russian designers is the territorial branding creation. In this regard, the students were asked to develop a logo sign taking into account the regional identification of the Don region. The deliberate restriction of the analysis direction within the framework of the key regional features of the territory helps to focus the students on the study of the chosen topic.

The teacher needs to control the disclosure of local content and direct the students' consciousness to the most characteristic forms, identifiers of the cultural and natural characteristics of the Don land. The patriotic education of the design students is the correct guidelines development point: in the framework of the chosen direction with the thematic limitations, the students create a unique content, maximally revealing its figurative potential.

It is important that in the performance of this task, blind borrowing from publicly available Internet sources pinterest, behance is excluded. The characteristic features of the region have a pronounced specificity, which motivates the students to search for a unique solution. Authorship and originality of the idea are a determining factor in setting the priorities for solving the problem.

The stage of understanding the topic should not take much time when working on the project and may be limited to the introductory lesson. The requirement to work within fixed deadlines develops the responsibility of the future designer and the ability to plan. For those who can't decide on an idea within the given time frame, there is a list of indicative topics to start the analysis and search process. The teacher's desire to inspire the student, talk about possible solutions is a powerful incentive for further work.

\section{Analysis and systematization of the source material}

The next stage of the project is based on the analog method of design. It is carried out in the form of an independent students' work. At this point, the collection and systematization of the source material. All images of the selected topic are classified according to three components:

- pictures - to make mostly own photos the student needs to independently analyze, select interesting and expressive images for studying the chosen topic. For example, to create a sign, the prototype of which is corn, it is necessary to study how it grows, how leaves, flowers, fruits look, how fields look, what are characteristic colors, shapes, texture, scale.

- text associations - to compile a list of synonyms, figurative associations, puns associated with this word or concept. For example, for the image of corn, verbal associations are suitable: yellow, juicy, ear, field, green, delicious, summer, July, sea, corn! salty, salt, queen of the fields, cone, grains, sweet, canned, shallow, crab, tender, etc.

- illustrative image - to search on the sites as analogues of ready-made illustrations that will help the student to determine the graphic language in the author's solution; it can be patterns, logos, drawings, graphic stylization. The student's ability to select the suitable 
options and build arguments to justify the choice is one of the important points in the development and formation of the designer as a professional.

The analogues' accumulation and systematization stage are the basis for further work. Its duration can be limited by a one-time extracurricular task with the subsequent continuation and the development in the course of generating the author's idea. An individual approach to learning enables each student to formulate his own concept in stages and improve the result in a gradual process.

\section{Creating a composite logo structure}

The task of any artistic creation is to create a composition. The solution to this problem is the systematic organization of the form, whether it is three-dimensional, existing in space, or two-dimensional, which is a planar image. Like any dialectical process, the compositional search uses the method from abstract to concrete. This method in the students' imaginative thinking formation context is described in the educational program of the Russian architect and teacher Nikolai Ladovsky, who was innovative for his time, who taught a course of architectural composition at the Higher art and technical workshops in the 1920 s $[3,4]$.

The purpose of the method is to obtain the skills in working with the form, which is the basis of the compositional solution. In graphic design through the figurative compositions' creation, the most holistic image of the topic being developed is achieved. The elements of the graphic design language are iconic images, fonts, color, tone, texture. Their combined use makes it possible to create an expressive logo, causing the viewer a certain set of associations and emotional reactions [5].

Creating a composition is a clearly defined sequence. The composite thinking formation for a student is a significant difficulty for the teacher. Therefore, the whole process should be divided into the stages with a gradual complication of the task and the concretization of its results. First, the students are given the expression of their ideas in the form of schematic images of the form, and then - by means of tone, contrast, color, texture use.

At the beginning of the work, image structuring is performed in the form of square compositions assembled into a general compositional scheme. Compositional unity and integrity a priori are the main condition for the harmonization of the graphic form. According to the world practice analysis in graphic design, compositions can be exclusively copyrighted with an absolutely original idea, and can be a replica of an existing solution and allow borrowing, but not more than $40 \%$ of the original sample. The latter case is justified if the topic has a historical aspect, relates to a specific person, or it is impossible to take own photos for a number of reasons [6].

Photographs, font blocks, patterns and drawings can be limited to the square shape of the composition. As dominant, such compositional means as plastic form, scale, angle, rhythm, contrast, color, texture, transparency can be used.

In photographs, the framing scale and placement of the composition focus, the horizon and the elements' proportions are important. A necessary condition for expressiveness is foreshortenning, it can be a frontal frame, from above, from below, from the sides, general plan, macro photography, detailing with cropping. Different times of day are allowed. The use of color filters and monochrome image options are welcomed in the final decision for the dominants' harmony.

Font compositions contain letters and words that are characteristic of the subject and semantics of a concept. A restriction is introduced on the choice of font and its properties. A composition from one letter is possible, as well as from a full phrase. Background is involved in creating the composition as an independent component. Perhaps the punctuation marks can be additionally used to enhance the emotional effect of the font. The 
combination of photographs and text within the same composition is extremely undesirable, because there is a possibility of violation of unity.

Font is one of the most effective sources of inspiration and turnkey solutions. With a simple bust, it is possible to find a unique combination of characters and create a unique idea for the logo. Accidental fonts should not be dominant in this project, the preferences are given to the simplest in shape chopped fonts: Helvetica, Freeset, Futura, Din, Meta, Helios, etc. [7]. In the search for the letters and words' compositions, an understanding of the font and the possibility of working with it is opened up. This is a very important educational moment in getting to know typography as the most important compositional component of a logo [8].

The illustrative part is the most creative component of the project, which makes it possible to express the concept as effectively as possible through the author's style. All emphasis in this part of the work is transferred to the development of the personal vision, which is revealed in the search for original forms of expression. The desire to maintain the techniques' integrity is necessarily reinforced by copying font techniques, finds. Therefore, repeating compositions from the patterns and vice versa - the patterns from letters - creates a system of roll-call and accompaniment for the main components of the composition. It is from this path that is in need to go to the final stage, which consists in finding a conceptual solution to the logo.

\section{Formation of the final solution to the design problem}

At the final stage of the educational project's implementation, the characteristics of the selected option are refined as the most accurately expressing the idea of the author and corresponding to the task of revealing the project task's topic.

Acquaintance with the aesthetics of creating a logo for a student studying graphic design should occur gradually and consistently. Therefore, the structural analysis and study of all the features of the selected thematic areas stimulates ready-made solutions. Moreover, these decisions are backed up by the research and the analytical base. Also, all the techniques of composition using specific elements of the graphic design language should be worked out. At this stage, it is important that the teacher helps in selecting the necessary options, which can guide the student to the most appropriate solution.

Typically, a situation analysis is carried out on the basis of 2-3 logo options that are well developed and may be different in structure. This approach is of particular importance, since working at the search stage only on one option, the student loses the ability to variability and to a critical approach, which can negatively affect the result.

The experience for a group discussion of the options proposed by the student is useful. The opinions from the outside will help the student, on the one hand, to learn to present their ideas with a reason, and on the other, to hear the advice of their colleagues. It is important to distinguish between constructive criticism and random opinion. But do not exaggerate the importance of the students' discussion, as this is only the opinion of novice professionals who have too little experience in the field of design. The final conclusion belongs to the teacher.

Exit to the final decision can be supplemented and transformed. It is at this stage that it is important to analyze how accurately the answers to the problems of creating a logo are found:

- how accurately the logo forms an idea of the chosen direction;

- whether it gives the unnecessary and excessed images;

- whether a unique image of the Don region is created within the framework of a given topic;

- whether the logo has an accessible and understandable graphic form; 
- whether it is easy to perceive and remember;

- how it will be implemented on media (from printing on small souvenir products to placement on outdoor advertising, from magazine pages to Youtube channel);

- whether the logo is harmonious and pleasant in terms of the overall composition.

There can be many such questions, it all depends on the image and the chosen topic. It is important to get practical answers, and if doubts and unacceptable answers, such as the inability to put a complex logo on the handle remain, it is necessary to return to the options' stage or to revise the options' concept and make assumptions in a possible special version of the minimum logo size.

Figure 1 shows the signs of regional identification of the Don region, developed by the design students of the Don State Technical University.

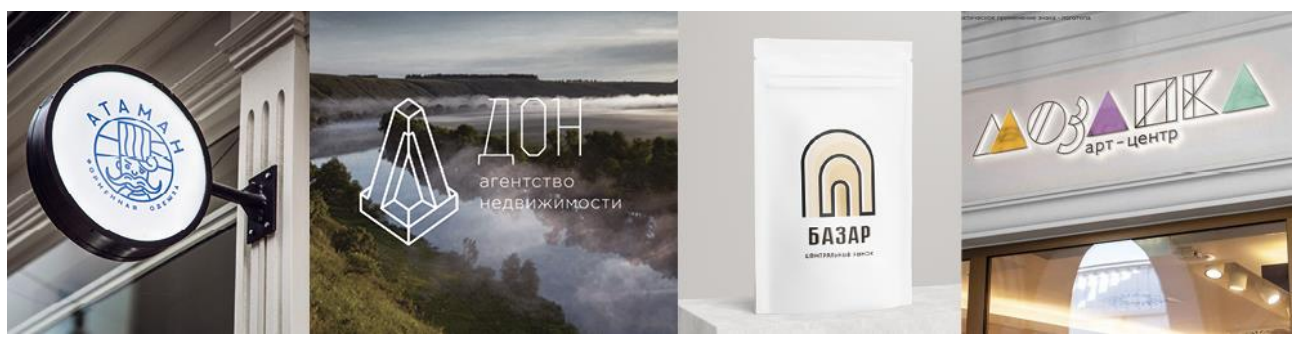

Fig. 1. Signs of the Don region regional identification (project: Don State Technical University).

\section{Summary}

Design refers to creative professions. artistic intuition and some spontaneity are the characteristic feature of it, as of any other type of art [9]. However, to achieve a positive result, the designer always relies on research methods for setting, analyzing and effectively solving the design problem. Therefore, at the training stage, it is important to acquire the ability to structure and systematize the process. When creating a logo, this competency is fully formed.

The logo, as the main identification component of visual branding, is a communication tool between the company and the consumer of its products. The logo combines both semantic information, which is responsible for conveying the message meaning, and the aesthetic information, which forms the attitude to the brand [2]. The dependence of the designer on inspiration in this process is practically eliminated.

The designer should form an artistic and expressive solution to the logo based on logic and a methodological approach. The design method for creating a logo is not limited to a compositional solution, but accumulates several related professional fields at once, such as social psychology, marketing, statistics and analytical research, advertising, history, geography and many others. It is important to form a comprehensive vision of the problem for the student. Therefore, an accessible and reasonable assessment system creates an understanding of design as the main determining element in creating a brand whose face is the logo. The described technique is a sequential algorithm of actions that forms the necessary professional competencies for the future designer and leads to a successful result.

\section{References}

1. R. Malinic, Book of Branding - a guide to creating brand identity for startups and beyond Paperback (Brand Nu, United Kingdom, 2019) 
2. I. Klimenko, T. Berdnik, A LUMEN Peer Reviewed Journal 9(2) (2018) https://lumenpublishing.com/journals/index.php/po/article/view/555

3. N. Ladovsky, Fundamentals of building a theory of architecture (under the sign of rationalistic aesthetics) (News ACHOBA, Moscow, 1926)

4. C. Gray, The Russian Experiment in Art (Thames and Hudson, London, 1976)

5. B. Elbrunn, 53 Logo Per. with french under the editorship of S. G. Bozhuk (OLMAPRESS Invest, Moscow, 2003)

6. M. Rose, Brand(ing) Independence Logos 29(4), 7-13 (2019) https://doi.org/10.1163/18784712-02904002

7. D. Devshivili, Century Helvetica. Queen of the grotesques or the most ordinary font Designer 3, 14 - 19 (2003)

8. J, Chichold, New typography. A Guide for a Modern Designer (Artemy Lebedev Studio, Moscow, 2018)

9. I. Dobritsyna, From postmodernism to nonlinear architecture: architecture in the context of modern philosophy (Progress-Traditsia, Moscow, 2004) 